\title{
DTA-H19 Plasmid
}

National Cancer Institute

\section{Source}

National Cancer Institute. DTA-H19 Plasmid. NCI Thesaurus. Code C64845.

A plasmid DNA encoding the A chain of the diphtheria toxin (DT-A) driven by the transcriptional regulatory sequences of human $\mathrm{H} 19$, with potential antineoplastic activity. Because the expression of DT-A is under the control of $\mathrm{H} 19$ promotor elements, DT-A is selectively expressed in tumor cells capable of turning on H-19. DT-A catalyzes ADPribosylation of translation elong ation factor 2 (EF-2), resulting in the inhibition of protein synthesis and apoptosis. In addition, DT-A protein released from lysed cells cannot enter and kill neighboring cells because of the absence of the DT-B chain, further enhancing the selective cytotoxicity of this agent. Human $\mathrm{H} 19$ is a paternally-imprinted, oncofetal gene encoding an RNA product; it acts as a riboregulator in gene expression and is found at substantial levels in different human tumor cell types while its expression in normal adult tissue is limited. 